\title{
Rendimento quântico e trocas gasosas em maracujazeiro amarelo sob salinidade hídrica, biofertilização e cobertura morta ${ }^{1}$
}

\author{
Quantum yield and gas exchange in yellow passion fruit under salinity water, \\ biofertilization and mulch
}

\author{
José Lucínio de Oliveira Freire ${ }^{2 *}$, Thiago Jardelino Dias ${ }^{3}$, Lourival Ferreira Cavalcante ${ }^{4}$, Pedro Dantas \\ Fernandes ${ }^{5}$ e Antonio João de Lima Neto ${ }^{6}$
}

\begin{abstract}
RESUMO - Um experimento foi conduzido a céu aberto no município de Remígio, PB, para se avaliar as respostas do maracujazeiro amarelo relacionadas à eficiência fotossintética e trocas gasosas. O delineamento experimental utilizado foi em blocos casualizados, no esquema fatorial 2 x 2 x 2, referente à irrigação com água não salina $\left(0,5 \mathrm{dS} \mathrm{m}^{-1}\right)$ e salina $\left(4,5 \mathrm{dS} \mathrm{m}^{-1}\right)$, sem e com biofertilizante bovino, sem e com cobertura morta, com três repetições e três plantas por parcela, em recipientes plásticos circulares utilizados como lisímetros de pressão, com $130 \mathrm{dm}^{3}$ de volume e drenos na parte inferior para a lixiviação do excesso de sais. A irrigação com água de baixa salinidade e aplicação de biofertilizante bovino comum estimularam a eficiência fotossintética das plantas. O uso simultâneo de água de alta salinidade, biofertilizante e cobertura morta reduziram a condutância estomática do maracujazeiro amarelo. As plantas sob estresse salino apresentaram atividade fotoquímica do fotossistema II e fotossíntese líquida inibida.
\end{abstract}

Palavras-chave: Fotossíntese líquida. Fluorescência. Condutância estomática. Esterco líquido.

\begin{abstract}
The experiment was conducted in Remigio, Paraiba State, to evaluate the responses of yellow passion fruit (Passiflora edulis Sims f. flavicarpa Degener) related to photosynthetic efficiency and gás exchange, mineral nutrition, water consumption yield and water use efficiency by plants. The experimental design was randomized blocks in a $2 \times 2 \times 2$ factorial, related to irrigation with not saline $\left(0.5 \mathrm{dS} \mathrm{m}^{-1}\right)$ and saline water $\left(4.5 \mathrm{dS} \mathrm{m}^{-1}\right)$, soil with and without biofertilizer, with and without mulch, in three replications. Three plants were maintained in plastic containers used as pressure circular lysimeters with $130 \mathrm{dm}^{3}$ volume and drains to the leaching of salts excess. Irrigation water with low salinity and application of biofertilizer common stimulated photosynthetic efficiency of plants. Simultaneous use of high salinity water, fertilizer and mulch to reduced stomatal conductance of yellow passion fruit. Plants under salt stress have photochemical activity of photosystem II and inhibited net photosynthesis.
\end{abstract}

Key words: Net photosynthesis. Fluorescence. Stomatal conductance. Manure liquid.

\footnotetext{
*Autor para correspondência

${ }^{1}$ Recebido para publicação em 02/08/2012; aprovado em 20/09/2013

Parte da Tese de Doutorado do primeiro autor, PPGA/CCA/UFPB, pesquisa financiada pelo Conselho Nacional de Desenvolvimento Cientifico e Tecnológico $(\mathrm{CNPq})$

${ }^{2}$ Instituto Federal de Educação, Ciência e Tecnologia da Paraíba/IFPB, Campus Picuí-PB, Brasil, lucinio@folha.com.br,

${ }^{3}$ Departamento de Agropecuária do Centro de Ciências Humanas, Sociais e Agrárias da Universidade Federal da Paraíba (DAP/CCHSA/UFPB), Bananeiras-PB, Brasil, thiago@cchsa.ufpb.br

${ }^{4}$ Centro de Ciências e Tecnologia Agroalimentar, Universidade Federal de Campina Grande, CCTA/UFCG, Pombal-PB, Brasil, lofeca@ cca.ufpb.br ${ }^{5}$ Centro de Ciências Agrárias e Ambientais, Universidade Estatual da Paraíba, CCAA/UEPB, Lagoa Seca-PB, Brasil, pdantas@cnpq.br ${ }^{6}$ Programa de Pós-Graduação em Agronomia (Produção Vegetal), Universidade Estatual de São Paulo, Jaboticabal-SP, Brasil, limanetoagro@ hotmail.com
} 


\section{INTRODUÇÃO}

Na região semiárida do Nordeste brasileiro, o manejo da cultura do maracujazeiro amarelo (Passiflora edulis Sims f. flavicarpa Deg.) depende da irrigação, em muitos casos efetuada com água com alto teor de sais (CAVALCANTE et al., 2011), o que pode induzir modificações fisiológicas e comprometer o crescimento e desenvolvimento das plantas.

A salinidade é um dos estresses abióticos que mais limita o crescimento, desenvolvimento e a produtividade das plantas em todo o mundo. No maracujazeiro amarelo, são relatados reflexos negativos decorrentes da irrigação de plantas com águas de diferentes níveis de salinidade no consumo hídrico (FREIRE et al., 2011) e atributos qualitativos externos e internos dos frutos (FREIRE et al., 2010).

Submetidas a estresses abióticos ou ambientais, as plantas apresentam sintomas de alterações no estado funcional das membranas dos tilacóides dos cloroplastos, que provocam mudanças nas características dos sinais de fluorescência, quantificados nas folhas pela fluorescência inicial $\left(\mathrm{F}_{0}\right)$, máxima $\left(\mathrm{F}_{\mathrm{m}}\right)$ e variável $\left(\mathrm{F}_{\mathrm{v}}\right)$ da clorofila $a$, além do rendimento quântico potencial $\left(\mathrm{F}_{\mathrm{v}} / \mathrm{F}_{\mathrm{m}}\right)$ (CHAUM; KIRMANEE, 2011; SILVA et al., 2011).

O funcionamento do fotossistema II (PSII) é um indicador da eficiência no uso da radiação fotoquímica $\mathrm{e}$, consequentemente, na assimilação de carbono pelas plantas, auxiliando no diagnóstico da integridade do aparato fotossintético frente às adversidades ambientais (TESTER; BACIC, 2005). A condutância estomática de genótipos de Cucumis melo, que é planta $\mathrm{C}_{3}$, é reduzida quando submetidas a estresses salinos, comprometendo a taxa de crescimento e a produtividade final (KUSVURAN, 2012).

A sensibilidade das culturas aos sais da água e do solo evidencia a necessidade de pesquisas que tenham como meta a obtenção de tecnologias viáveis para os produtores e que possam minimizar os efeitos deletérios da salinidade às plantas, já que é quase obrigatória, a utilização de águas salinas na agricultura em regiões semiáridas (SOUZA et al., 2012).

A utilização de técnicas e de biofertilizante produzido a partir da fermentação anaeróbica do esterco bovino fresco, com o intuito de reduzir os efeitos depressivos da salinidade da água, ou do solo, são possibilidades testadas nos últimos anos para minimizar os problemas de salinização dos solos e viabilizar o uso de águas salinas na agricultura irrigada (CAVALCANTE et al., 2010; DIAS et al., 2011; SOUZA et al., 2012).

A cobertura do solo com restos vegetais vem sendo utilizada com a finalidade de diminuir a evaporação da água disponibilizada às plantas, evitando o incremento da concentração salina e promovendo depleção nos quantitativos de sais na superfície do solo e próximo à zona radicular das plantas (PERES et al., 2010).

O objetivo da pesquisa foi avaliar respostas comportamentais do maracujazeiro amarelo irrigado com águas de baixa e alta salinidade, em solo sem e com biofertilizante bovino, sem e com cobertura morta, relacionadas à eficiência fotoquímica e trocas gasosas.

\section{MATERIAL E MÉTODOS}

O experimento foi conduzido entre setembro de 2009 e abril de 2010 em pomar aberto, no município de Remígio, Estado da Paraíba, inserido na Mesorregião Agreste e Microrregião Curimataú Ocidental e georreferenciado pelas coordenadas geográficas de 6 ${ }^{\circ} 53^{\prime} 00^{\prime \prime}$ de latitude Sul, 36 $32^{\circ} 00^{\prime \prime}$ de longitude Oeste e altitude de $470 \mathrm{~m}$. O clima do município, segundo Köppen (COELHO; SONCIN, 1982) é do tipo As', quente e seco com umidade relativa e temperatura média anual do ar variando de 70 a $80 \%$ e $24^{\circ} \mathrm{C}$. A pluviosidade no período experimental foi de $166 \mathrm{~mm}$.

O substrato utilizado constou de uma mistura dos primeiros $10 \mathrm{~cm}$ de um ARGISSOLO AMARELO LATOSSÓLICOEutrófico, não salino (SANTOS et al., 2006), com esterco bovino de relação C/N 16/1, com teor de umidade de $12 \%$, na proporção em volume de 10:1 (solo/esterco bovino), (CAVALCANTE et al., 2007). As características de fertilidade e salinidade do substrato, contidas na Tabela 1, foram obtidas conforme metodologias compiladas pela Embrapa (1997) e Richards (1954), respectivamente.

O experimento foi implantado no esquema fatorial $2 \times 2 \times 2$, em blocos casualizados, com três repetições e unidade experimental representada por três plantas de maracujazeiro amarelo, transplantadas no arranjo espacial de $3,0 \times 3,0 \mathrm{~m}$, para recipientes plásticos de $60 \mathrm{~cm}$ de diâmetro e $50 \mathrm{~cm}$ de altura, utilizados como lisímetros de pressão, contendo $130 \mathrm{dm}^{3}$ de substrato composto por solo + esterco bovino. Os fatores em estudo consistiram de irrigação com águas de baixa $\left(0,50 \mathrm{dS} \mathrm{m}^{-1}\right)$ e alta salinidade $\left(4,50 \mathrm{dS} \mathrm{m}^{-1}\right)$, sem e com aplicação de biofertilizante bovino comum, sem e com cobertura morta.

As irrigações foram efetuadas diariamente, utilizando-se provetas volumétricas, com reposição de um volume hídrico correspondente a $20 \%$ da lâmina de água evaporada no dia precedente, medida com o auxilio do tanque Classe "A" instalado em um local adjacente à área experimental. A irrigação real necessário foi determinada de acordo com os valores estimados pelo método do tanque descontando os valores de precipitação $(\mathrm{mm})$ registrados no período de execução desse ensaio. A frequência de lixiviação foi de 7 (sete) 
Tabela 1 - Composição química e salinidade do substrato (solo + esterco bovino) utilizado nos tratamentos. Remígio, PB, 2010

\begin{tabular}{|c|c|c|c|}
\hline Complexo sortivo & Valores & Salinidade & Valores \\
\hline pH (água: 1:2,5) & 6,2 & $\mathrm{pH}$ & 6,8 \\
\hline $\mathrm{P}\left(\mathrm{mg} \mathrm{dm}^{-3}\right)$ & 79,85 & $\mathrm{CE}\left(\mathrm{dS} \mathrm{m^{-1 } )}\right.$ & 3,10 \\
\hline $\mathrm{K}^{+}\left(\mathrm{mg} \mathrm{dm} \mathrm{m}^{-3}\right)$ & 124,00 & $\mathrm{Ca}^{2+}\left(\mathrm{mmol}_{\mathrm{c}} \mathrm{L}^{-1}\right)$ & 8,80 \\
\hline $\mathrm{Na}^{+}\left(\mathrm{cmol}_{\mathrm{c}} \mathrm{dm}^{-3}\right)$ & 0,29 & $\mathrm{Mg}^{2+}\left(\right.$ mmolc L $\left.{ }^{-1}\right)$ & 5,00 \\
\hline $\mathrm{Ca}^{2+}\left(\mathrm{cmol}_{\mathrm{c}} \mathrm{dm}^{-3}\right)$ & 3,95 & $\mathrm{~K}^{+}\left(\mathrm{mmol}_{\mathrm{c}} \mathrm{L}^{-1}\right)$ & 2,40 \\
\hline $\mathrm{Mg}^{2+}\left(\mathrm{cmol}_{\mathrm{c}} \mathrm{dm}^{-3}\right)$ & 1,10 & $\mathrm{Na}^{+}\left(\mathrm{mmol}_{\mathrm{c}} \mathrm{L}^{-1}\right)$ & 14,95 \\
\hline $\mathrm{SB}\left(\mathrm{cmol}_{\mathrm{c}} \mathrm{dm}^{-3}\right)$ & 5,65 & $\mathrm{SO}_{4}^{2}-\left(\mathrm{mmol}_{\mathrm{c}} \mathrm{L}^{-1}\right)$ & 5,60 \\
\hline $\mathrm{H}++\mathrm{Al}^{3+}\left(\mathrm{cmol}_{\mathrm{c}} \mathrm{dm}^{-3}\right)$ & 1,65 & $\mathrm{CO}_{3}^{2-}\left(\mathrm{mmol}_{\mathrm{c}} \mathrm{L}^{-1}\right)$ & Ausente \\
\hline $\mathrm{Al}^{3+}\left(\mathrm{cmol}_{\mathrm{c}} \mathrm{dm}^{-3}\right)$ & Ausente & $\mathrm{HCO}^{3-}\left(\mathrm{mmol}_{\mathrm{c}} \mathrm{L}^{-1}\right)$ & 8,17 \\
\hline $\mathrm{CTC}_{\mathrm{pH} 7,0}\left(\mathrm{cmol}_{\mathrm{c}} \mathrm{dm}^{-3}\right)$ & 7,30 & $\mathrm{Cl}^{-}\left(\mathrm{mmol}_{\mathrm{c}} \mathrm{L}^{-1}\right)$ & 16,97 \\
\hline $\mathrm{m}(\%)$ & 0,00 & $\operatorname{RAS}\left(\mathrm{mmol} \mathrm{L}^{-1}\right)^{1 / 2}$ & 5,69 \\
\hline $\mathrm{V}(\%)$ & 77,39 & $\operatorname{PST}(\%)$ & 3,97 \\
\hline M.O. $\left(\mathrm{g} \mathrm{kg}^{-1}\right)$ & 11,81 & Classificação & Não salino \\
\hline $\mathrm{B}\left(\mathrm{mg} \mathrm{dm}^{-3}\right)$ & 0,62 & & \\
\hline $\mathrm{Fe}\left(\mathrm{mg} \mathrm{dm}^{-3}\right)$ & 36,04 & & \\
\hline $\mathrm{Cu}\left(\mathrm{mg} \mathrm{dm}^{-3}\right)$ & $<\mathrm{ADL}$ & & \\
\hline $\operatorname{Mn}\left(\mathrm{mg} \mathrm{dm}^{-3}\right)$ & 6,80 & & \\
\hline $\mathrm{Zn}\left(\mathrm{mg} \mathrm{dm}^{-3}\right)$ & 1,04 & & \\
\hline
\end{tabular}

$\mathrm{SB}=$ Soma de bases $\left(\mathrm{Ca}^{2+}+\mathrm{Mg}^{2+}+\mathrm{Na}^{+}+\mathrm{K}^{+}\right) ; \mathrm{CTC}=$ Capacidade de troca catiônica $\left[\mathrm{SB}+\left(\mathrm{H}^{+}+\mathrm{Al}^{3+}\right)\right] ; \mathrm{m}=$ Saturação em alumínio; $\mathrm{V}=\mathrm{Saturação} \mathrm{de}$ bases $\left[(\mathrm{SB} / \mathrm{CTC})^{*} 100\right] ; \mathrm{M} . \mathrm{O}=$ Matéria orgânica; $] ; \mathrm{ADL}=$ Aquém do limite de detecção; $\mathrm{CE}=$ Condutividade elétrica; $\mathrm{PST}=$ percentagem de sódio trocável; RAS = Razão de adsorção de sódio $\left[\mathrm{Na}^{+} /\left(\mathrm{Ca}^{2+}+\mathrm{Mg}^{2+} / 2\right)^{1 / 2}\right]$

dias, com utilização de uma fração de lixiviação $\left(\mathrm{F}_{\mathrm{L}}\right)$, em cada lisímetro, de $10 \%$ do volume de água aplicado até o dia da lixiviação correspondente. $\mathrm{A}_{\mathrm{L}}$ foi aplicada após o substrato atingir a capacidade de campo. A água de menor condutividade elétrica era proveniente de uma fonte superficial da propriedade. Após diluição com água de salinidade elevada (CE de 9,50 dS m $\mathrm{m}^{-1}$ ), procedente de fonte superficial, foi obtido o nível de salinidade da água dos tratamentos com água de 4,5 dS m $\mathrm{m}^{-1}$.

O biofertilizante bovino foi obtido a partir da fermentação anaeróbica do esterco bovino fresco misturado com água não clorada, na proporção de 1:1 (100 $\mathrm{dm}^{3}$ de cada componente), em recipiente com capacidade para $240 \mathrm{dm}^{3}$, hermeticamente fechado por um período mínimo de 30 dias, quando o $\mathrm{pH}$ foi de, aproximadamente, 7,0 (SANTOS; AKIBA, 1996). Depois de fermentado, o biofertilizante líquido foi diluído em água na proporção de 1:1 e aplicado na superfície do substrato contido nos lisímetros uma semana antes do plantio e a cada 90 dias, até o final do experimento em volume de $10 \mathrm{dm}^{3}$ planta $^{-1}$.

A cobertura morta foi feita com uma camada de $10 \mathrm{~cm}$ de capim seda (Cynodon dactylon L.) e posta na superfície dos recipientes plásticos utilizados como lisímetros de pressão, onde a muda do maracujazeiro foi plantada, com reposição a cada dois meses.

As plantas foram conduzidas em espaldeiras verticais, com um fio de arame liso $\mathrm{n}^{\mathrm{o}} 12$, situado a 2,30 $\mathrm{m}$ da superfície do solo, preso e esticado por mourões espaçados de três metros. A poda dos dois ramos laterais foi efetuada quando ambos atingiram 1,5 m de distância da haste principal.

As medições de emissão da fluorescência da clorofila $a$ foram efetuadas aos 92 DAT (dias após o transplantio das mudas), correspondente ao início da floração das plantas e aos 214 DAT, correspondente ao período de plena frutificação, entre as 10:00' e 11:15' horas da manhã, na folha mediana do ramo produtivo intermediário da planta, utilizando-se fluorômetro modulado Plant Efficiency Analyser - PEA II ${ }^{\circledR}$ (Hansatech Instruments Co., UK). Para avaliações dos parâmetros de fluorescência máxima $\left(\mathrm{F}_{\mathrm{m}}\right)$, fluorescência variável $\left(\mathrm{F}_{\mathrm{v}}\right)$ e rendimento quântico potencial $\left(\mathrm{F}_{\mathrm{v}} / \mathrm{F}_{\mathrm{m}}\right)$ (MAXWELL; JOHNSON, 2000), foram colocadas pinças foliares (leaf clips) nas folhas selecionadas para as leituras, após 30 minutos de adaptação ao escuro (KONRAD et al., 2005). 
Nos mesmos períodos avaliativos e horários das determinações da fluorescência da clorofila $a$, foram realizadas medições das variáveis de trocas gasosas na folha mediana e intacta do ramo produtivo intermediário da planta, com o auxílio do analisador de gás carbônico a infravermelho portátil (IRGA), modelo $\mathrm{LCPro}^{+}$Portable Photosynthesis System ${ }^{\circledR}$ (ADC BioScientific Limted, UK), com temperatura ajustada a $25^{\circ} \mathrm{C}$, irradiação de $1800 \mu \mathrm{mol}$

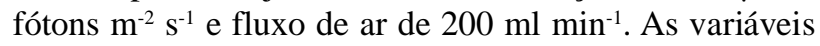
fisiológicas analisadas foram concentração interna de $\mathrm{CO}_{2}$ $\left(\mathrm{C}_{\mathrm{i}}-\mu \mathrm{mol} \mathrm{mol}{ }^{-1}\right)$, condutância estomática $\left(\mathrm{g}_{\mathrm{s}}-\mathrm{mol} \mathrm{m}^{-2} \mathrm{~s}^{-1}\right)$,

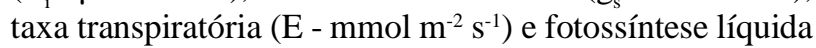
(A - expressa em $\mu \mathrm{mol} \mathrm{CO} \mathrm{Cm}^{-2} \mathrm{~s}^{-1}$ ).

Os resultados obtidos foram submetidos às análises de variância pelo teste de F e comparação de médias pelo teste de Tukey a $5 \%$ de probabilidade, de acordo com Banzatto e Kronka (2006), utilizando-se o Programa SAS STAT ${ }^{\circledR}$.

\section{RESULTADOS E DISCUSSÃO}

No início da floração do maracujazeiro amarelo, os tratamentos não exerceram efeitos significativos na $\mathrm{F}_{\mathrm{m}}$ das plantas (Tabela 2). Nos tratamentos com água de baixa salinidade $\left(0,5 \mathrm{dS} \mathrm{m}^{-1}\right)$, os valores de $\mathrm{F}_{\mathrm{m}}$ variaram de 3.095 a 2.924 elétrons quantum ${ }^{-1}$, respectivamente, nos tratamentos sem e com biofertilizante e sem cobertura do solo (Figura 1). Com a irrigação com água de alta salinidade $\left(4,5 \mathrm{dS} \mathrm{m}^{-1}\right)$, verificaram-se valores entre 2.712 e 2.999 elétrons quantum ${ }^{-1}$, respectivamente para situações sem e com biofertilizante e sem cobertura morta. Os dados
Figura 1 - Fluorescência máxima $\left(\mathrm{F}_{\mathrm{m}}\right)$ no final da fase produtiva do maracujazeiro amarelo irrigado com água de baixa e alta salinidade. Médias seguidas de mesmas letras não diferem estatisticamente entre si. DMS $=200,79$

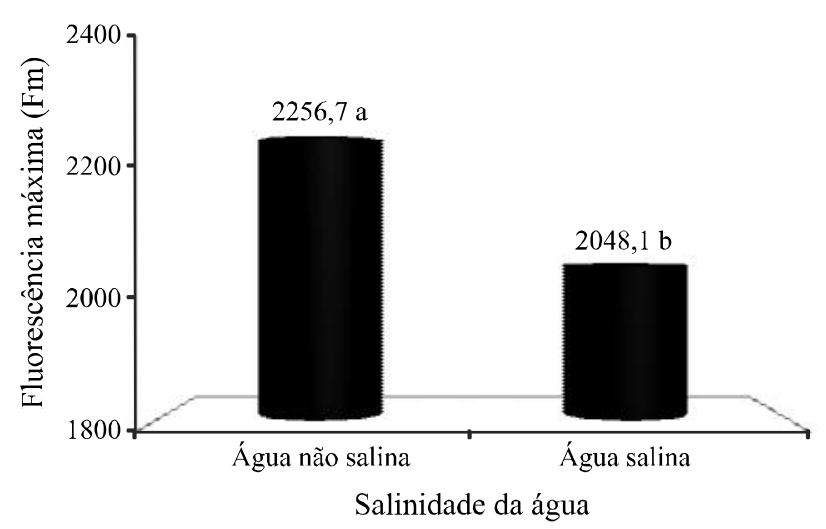

obtidos são concordantes com Correia et al. (2009), que não observaram efeitos significativos do incremento de salinidade na água de irrigação na $\mathrm{F}_{\mathrm{m}} \mathrm{em}$ amendoim.

No final da fase produtiva do maracujazeiro amarelo, a irrigação de plantas com água de maior teor salino influenciou negativamente a $\mathrm{F}_{\mathrm{m}}$, com depleção de 2.256,7 para 2.048,1 elétrons quantum ${ }^{-1}$ entre plantas tratadas com água de 0,5 e $4,5 \mathrm{dS} \mathrm{m}^{-1}$, respectivamente, com queda de $9,2 \%$ na fluorescência máxima (Figura 1). Para Lucena (2009), o estresse salino afeta negativamente a atividade fotossintética com alterações nos parâmetros do fotossistema.

Tabela 2 - Resumos das análises de variância, pelo quadrado médio, referentes à fluorescência máxima $\left(\mathrm{F}_{\mathrm{m}}\right)$, fluorescência variável $\left(\mathrm{F}_{\mathrm{v}}\right)$ e rendimento quântico potencial $\left(\mathrm{F}_{\mathrm{v}} / \mathrm{F}_{\mathrm{m}}\right)$ do maracujazeiro amarelo no início da floração ${ }_{(1)}$ e encerramento da fase produtiva ${ }_{(2)}$

\begin{tabular}{lcccccc}
\hline \multirow{2}{*}{ Fonte de Variação } & \multicolumn{5}{c}{ Quadrados Médios } \\
\cline { 2 - 7 } & $\mathrm{GL}$ & $\mathrm{Fm}$ & $\mathrm{Fv}_{(1)}$ & $\mathrm{F}_{\mathrm{v}(2)}$ & $\mathrm{F}_{\mathrm{v}} / \mathrm{Fm}_{(1)}$ & $\mathrm{F}_{\mathrm{v}} / \mathrm{Fm}_{(2)}$ \\
\hline Blocos & 2 & $29,13^{\mathrm{ns}}$ & $37,07^{\mathrm{ns}}$ & $21085,00^{\mathrm{ns}}$ & $0,0013^{\mathrm{ns}}$ & $0,0004^{\mathrm{ns}}$ \\
Água (A) & 1 & $261,04^{* *}$ & $108,54^{*}$ & $445537,00^{*}$ & $0,0073^{*}$ & $0,0196^{* *}$ \\
Bio (B) & 1 & $119,99^{\mathrm{ns}}$ & $170,66^{\mathrm{ns}}$ & $248880,00^{\mathrm{ns}}$ & $0,0014^{\mathrm{ns}}$ & $0,0129^{*}$ \\
Cob (C) & 1 & $104,67^{\mathrm{ns}}$ & $76388,00^{\mathrm{ns}}$ & $117320,00^{\mathrm{ns}}$ & $0,0001^{\mathrm{ns}}$ & $0,0026^{\mathrm{ns}}$ \\
A x B & 1 & $47082,00^{\mathrm{ns}}$ & $10668,00^{\mathrm{ns}}$ & $50233,50^{\mathrm{ns}}$ & $0,0018^{\mathrm{ns}}$ & $0,0002^{\mathrm{ns}}$ \\
A x C & 1 & $5985,04^{\mathrm{ns}}$ & $69984,00^{\mathrm{ns}}$ & $6666,66^{\mathrm{ns}}$ & $0,0004^{\mathrm{ns}}$ & $0,00004^{\mathrm{ns}}$ \\
B x C & 1 & $345,04^{\mathrm{ns}}$ & $0,16666^{\mathrm{ns}}$ & $10333,5^{\mathrm{ns}}$ & $0,0002^{\mathrm{ns}}$ & $0,0035^{\mathrm{ns}}$ \\
A x B x C & 1 & $104,41^{\mathrm{ns}}$ & $79350,00^{\mathrm{ns}}$ & $109890,00^{\mathrm{ns}}$ & $0,0008^{\mathrm{ns}}$ & $0,0027^{\mathrm{ns}}$ \\
Resíduo & 14 & 52700,75 & 19341,30 & 57424,36 & 0,0013 & 0,0018 \\
CV (\%) & & 10,66 & 6,09 & 14,83 & 4,56 & 5,78 \\
\hline
\end{tabular}

$\mathrm{GL}=$ Grau de liberdade; $\mathrm{ns}=$ não significativo; $* \mathrm{e}^{* *}$ significativos aos níveis de $5 \%$ e $1 \%$, respectivamente; $\mathrm{CV}=\mathrm{Coeficiente} \mathrm{de} \mathrm{variação}$ 
No estádio fenológico de início da floração (Figura 2A), as plantas irrigadas com água de baixa salinidade apresentaram valores de $\mathrm{F}_{\mathrm{v}}$ de $2.347,4$ elétrons quantum $^{-1}$, com superioridade de $9,6 \%$ aos 2.212,9 quantum ${ }^{-1}$ observados nas plantas sob estresse salino. Com tendência semelhante e mais expressivamente, constata-se que, na Figura 2B, a elevação do teor salino da água de irrigação, ao final da fase produtiva do maracujazeiro amarelo, reduziu a $\mathrm{F}_{\mathrm{v}}$ das plantas de $1.751,7$ para $1.479,1$ elétrons quantum ${ }^{-1}$, com decréscimos de $15,6 \%$, e inibiu a atividade fotoquímica nas folhas.

A redução da fluorescência variável da clorofila $a$ das plantas, ao final da fase produtiva, evidencia que as condições abióticas analisadas promovem danos no aparelho fotossintético das plantas, comprometendo o $\mathrm{FS}_{\mathrm{II}}$, com o decorrer do tempo de exposição ao fator estressante.

$\mathrm{Na}$ fase de florescimento das plantas, o rendimento quântico potencial do fotossistema II foi influenciado significativamente pela salinidade da água. Conforme Figura 3, o incremento no teor salino da água até o início da floração reduziu a $\mathrm{F}_{\mathrm{v}} / \mathrm{F}_{\mathrm{m}}$ de 0,82 para 0,77 , com depleção de 6,1\%. Segundo Melo et al. (2010), nestas condições, o sistema fotossintético está intacto e não se observa inibição da atividade fotoquímica nos centros de reação do $\mathrm{FS}_{\mathrm{II}}$ das plantas. Os valores de $\mathrm{F}_{\mathrm{v}} / \mathrm{F}_{\mathrm{m}}$ obtidos nas plantas sob estresse salino refletem, baseando-se em Zanandrea et al. (2006) e Chaum e Kirdmanee (2011), o início de variações expressivas nas taxas de conversão da energia fotoquímica e não fotoquímica dissipada. No final da fase produtiva do maracujazeiro amarelo (Figura 4A), a irrigação com água de alta salinidade proporcionou uma depleção de $7,8 \%$ na $\mathrm{F}_{\mathrm{v}} / \mathrm{F}_{\mathrm{m}}$, o que, segundo Bolhàr-Nordenkampf et al. (1989), ao relatarem que a relação ideal deve estar entre 0,75 e 0,85 , reflete danos fotoinibitórios nos centros de reação do $\mathrm{FS}_{\mathrm{II}}$ nas plantas tratadas com água de alta salinidade. Correia et al. (2009) registraram reduções de 11,2\% no rendimento quântico potencial em amendoim com a elevação da salinidade da água de 0,4 para $6,0 \mathrm{dS} \mathrm{m}^{-1}$.

Os baixos valores de $\mathrm{F}_{\mathrm{v}} / \mathrm{F}_{\mathrm{m}}$ nas plantas sob estresse salino, provavelmente, são decorrentes do fechamento estomático e do declínio da fotossíntese líquida (SILVEIRA et al., 2010).

Figura 3 - Rendimento quântico potencial $\left(\mathrm{F}_{\mathrm{v}} / \mathrm{F}_{\mathrm{m}}\right)$ do maracujazeiro amarelo no início da floração sob irrigação com águas de baixa e alta salinidade. Médias seguidas de mesmas letras não diferem estatisticamente entre si. DMS $=0,03$

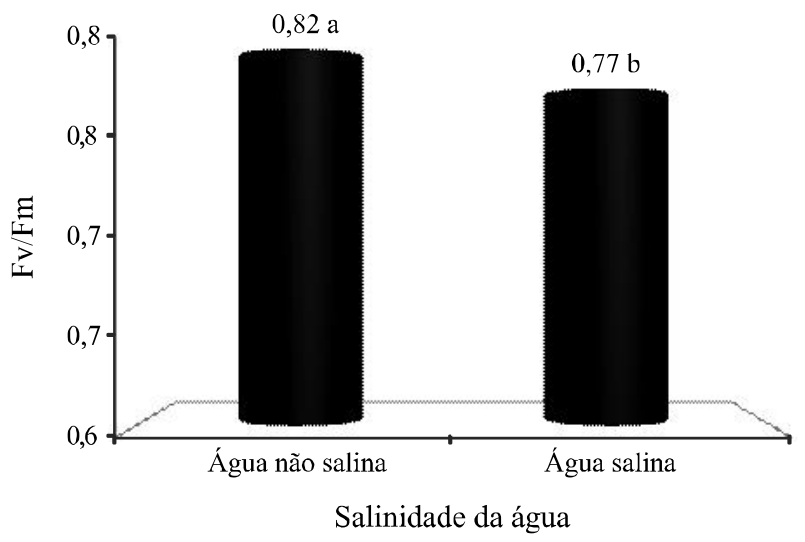

A aplicação do biofertilizante bovino elevou de 0,72 para 0,77 (Figura 4B) os valores de $\mathrm{F}_{\mathrm{v}} / \mathrm{F}_{\mathrm{m}}$. Essa elevação da $\mathrm{F}_{\mathrm{v}} / \mathrm{F}_{\mathrm{m}}$ de 0,72 para 0,77 nas plantas tratadas com biofertilizante bovino reforça as afirmações de Cavalcante et al. (2007) de que o insumo orgânico, por ser fonte de compostos bioativos, exerce ação positiva na nutrição das plantas e estimula a liberação de substâncias

Figura 2 - Fluorescência variável $\left(F_{v}\right)$ do maracujazeiro amarelo irrigado com água não salina e salina, no início da floração (A) e no final da fase produtiva (B). Médias seguidas de mesmas letras não diferem estatisticamente entre si. DMS (A) = 121,64; DMS (B) = 209,60
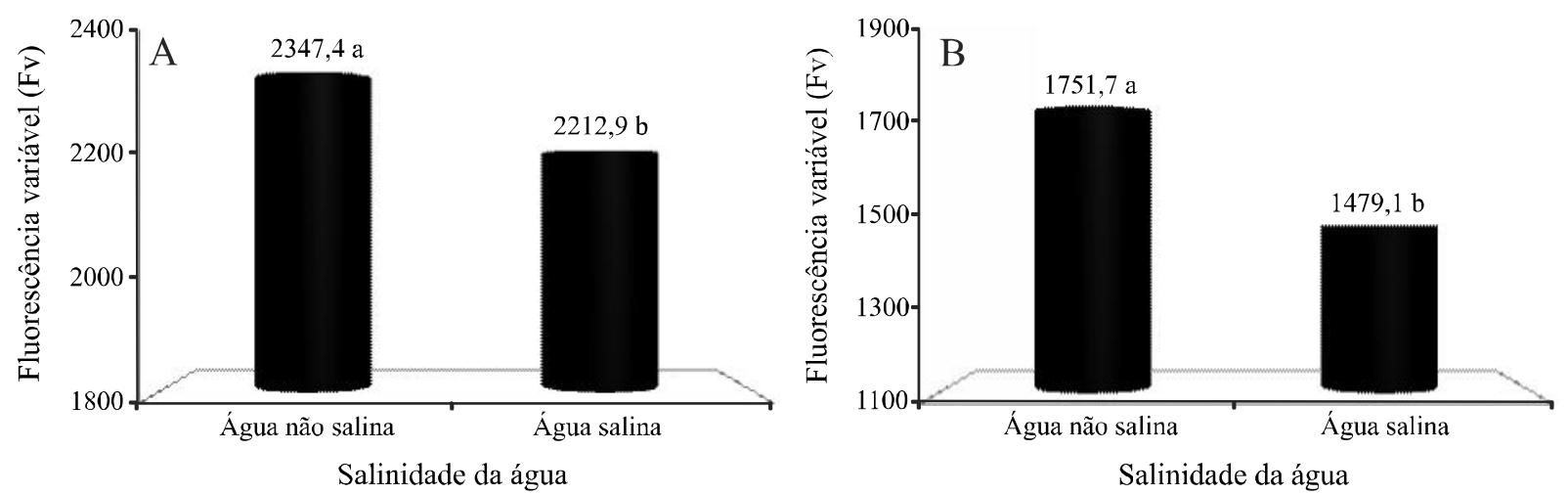
húmicas no solo, favorecendo maior atividade da enzima redutase e redução de aminoácidos livres, proporcionando maior acúmulo de $\mathrm{N}$ nas plantas, diminuindo o efeito do estresse hídrico e salino. Chaum e Kirdmanee (2011) asseveram que a matéria orgânica mitiga os efeitos deletérios dos sais à plantas com a elevação da eficiência quântica potencial da atividade química do $\mathrm{FS}_{\mathrm{II}}$.

Ocorreu queda na eficiência quântica potencial das plantas irrigadas com os dois níveis de salinidade da água entre os estádios de floração (Figura 3) e final da fase produtiva (Figura 4-A), justificada pela depleção nos teores de pigmentos fotossintéticos, reduções na razão $\mathrm{F}_{\mathrm{II}} / \mathrm{F}_{\mathrm{I}}$ e degradação dos componentes protéicos dos fotossistemas (FALQUETO et al., 2007).
No início da floração das plantas, nos tratamentos sem biofertilizante, a cobertura morta elevou a concentração interna de $\mathrm{CO}_{2}\left(\mathrm{C}_{\mathrm{i}}\right)$ de 206,2 a 235,7 $\mu \mathrm{mol} \mathrm{mol} \mathrm{m}^{-1}$, com acréscimos de $14,3 \%$, diferentemente dos tratamentos no solo com biofertilizante (Tabela 3) em que não se observou efeitos significativos da cobertura do solo (Figura 5A).

Nos tratamentos sem cobertura morta, observou-se maior $\mathrm{C}_{\mathrm{i}}$ nas plantas com biofertilizante em comparação com as que não receberam o insumo orgânico, em que

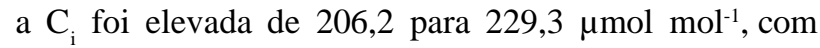
aumento de 11,2\%. Mesmo com tendência de redução, nos tratamentos com cobertura do solo não se observou efeito significativo com aplicação do efluente orgânico nos valores médios de $\mathrm{C}_{\mathrm{i}}$ Para Lyra et al. (2010), o uso da

Figura 4 - Rendimento quântico potencial $\left(\mathrm{F}_{\mathrm{v}} / \mathrm{F}_{\mathrm{m}}\right)$ ao final da fase produtiva do maracujazeiro amarelo irrigado com águas de baixa e alta salinidade (A), sem e com biofertilizante bovino (B). Médias seguidas de mesmas letras não diferem estatisticamente entre si. DMS =0,03

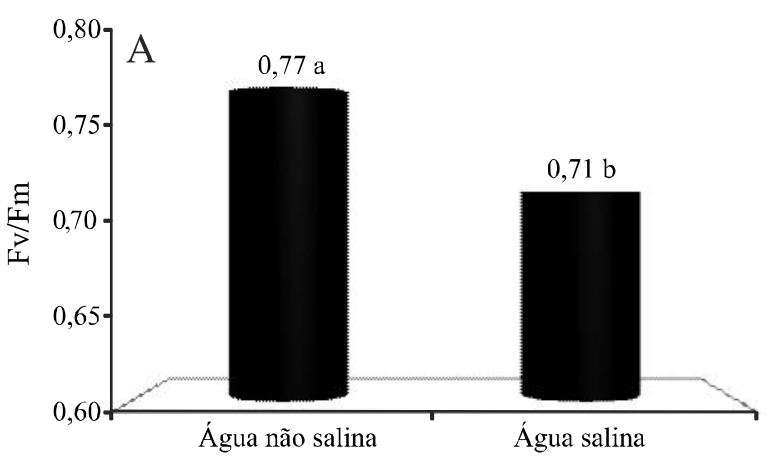

Salinidade da água

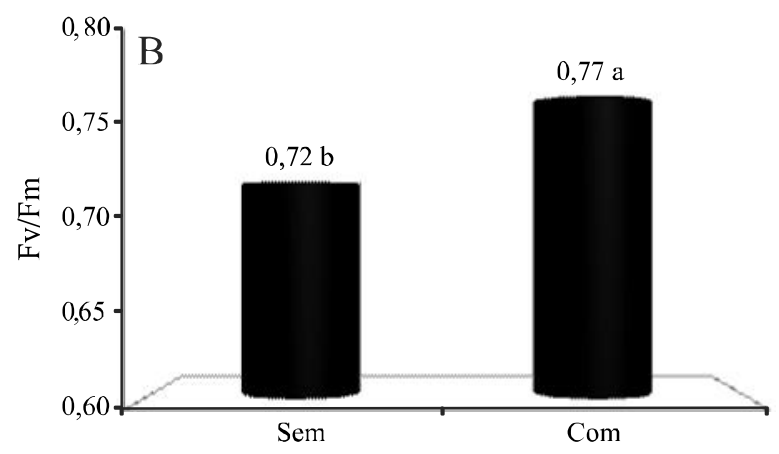

Biofertilizante bovino

Tabela 3. Resumos das análises de variância, pelo quadrado médio, referentes à concentração interna de $\mathrm{CO}_{2}\left(\mathrm{C}_{\mathrm{i}}\right)$, condutância estomática $\left(\mathrm{G}_{\mathrm{s}}\right)$ e taxa transpiratória (e) e fotossíntese líquida (A) do maracujazeiro amarelo no início da floração ${ }_{(1)}$ e encerramento da fase produtiva ${ }_{(2)}$

\begin{tabular}{|c|c|c|c|c|c|c|}
\hline \multirow{2}{*}{ Fonte de Variação } & \multicolumn{6}{|c|}{ Quadrados Médios } \\
\hline & $\mathrm{GL}$ & $\mathrm{Ci}_{(1)}$ & $\mathrm{Ci}_{(2)}$ & $\mathrm{Gs}_{(2)}$ & $E_{(2)}$ & $\mathrm{A}_{(2)}$ \\
\hline Blocos & 2 & $664,57^{\mathrm{ns}}$ & $240,84^{\mathrm{ns}}$ & $0,0001^{\mathrm{ns}}$ & $0,0382^{\mathrm{ns}}$ & $0,4446^{\mathrm{ns}}$ \\
\hline Água (A) & 1 & $1020,50^{\mathrm{ns}}$ & $5442,0 * *$ & $0,0016^{* *}$ & $0,2773^{\text {ns }}$ & $3,4808 *$ \\
\hline Bio (B) & 1 & $575,26^{\mathrm{ns}}$ & $80,67^{\mathrm{ns}}$ & $0,0016^{* *}$ & $0,4374 * *$ & $1,7496^{\mathrm{ns}}$ \\
\hline Cobertura (C) & 1 & $68,34^{\mathrm{ns}}$ & $244,48^{\mathrm{ns}}$ & $0,0002^{\text {ns }}$ & $0,0864^{\mathrm{ns}}$ & $2,0300^{\mathrm{ns}}$ \\
\hline$A \times B$ & 1 & $33,84^{\mathrm{ns}}$ & $333,01^{\mathrm{ns}}$ & $0,00001^{\mathrm{ns}}$ & $0,1472^{\mathrm{ns}}$ & $0,2016^{\mathrm{ns}}$ \\
\hline $\mathrm{A} \times \mathrm{C}$ & 1 & $429,26^{\mathrm{ns}}$ & $60,16^{\mathrm{ns}}$ & $0,0004^{\mathrm{ns}}$ & $0,0322^{\mathrm{ns}}$ & $0,0060^{\mathrm{ns}}$ \\
\hline $\mathrm{B} \times \mathrm{C}$ & 1 & $2330,50 * *$ & $655,21^{\mathrm{ns}}$ & $0,0020 * *$ & $0,7704 * *$ & $0,6403^{\mathrm{ns}}$ \\
\hline $\mathrm{A} \times \mathrm{B} \times \mathrm{C}$ & 1 & $14,26^{\mathrm{ns}}$ & $54,00^{\mathrm{ns}}$ & $0,0006^{*}$ & $0,1908^{\mathrm{ns}}$ & $0,6666^{\mathrm{ns}}$ \\
\hline Resíduo & 14 & 259,81 & 372,84 & 0,0018 & 0,0635 & 0,7151 \\
\hline $\mathrm{CV}(\%)$ & & 7,24 & 7,89 & 27,96 & 19,06 & 38,74 \\
\hline
\end{tabular}

GL = Grau de liberdade; ns = não significativo; * e ** significativos aos níveis de 5\% e 1\%, respectivamente; $\mathrm{CV}=$ Coeficiente de variação 
Figura 5 - Concentração interna de $\mathrm{CO}_{2}\left(\mathrm{C}_{\mathrm{i}}\right)$ em folhas de maracujazeiro amarelo em solo sem e com biofertilizante bovino na época da floração (A) e irrigado com águas não salina e salina, sem e com biofertilizante, no encerramento da fase produtiva (B). Médias seguidas de mesmas letras minúsculas entre as diferentes condições de uso da cobertura morta dentro das mesmas condições do uso de biofertilizante bovino e maiúsculas entre a mesma condição do uso de cobertura morta dentro de diferentes condições do uso de biofertilizante bovino (A) não diferem estatisticamente entre si. DMS (A) $=19,93$; DMS (B) $=16,88$

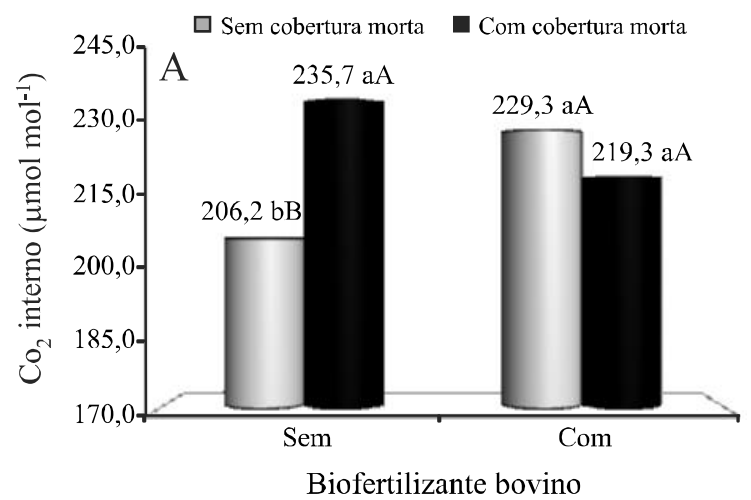

cobertura morta proporciona boas condições hídricas no solo, evitando a manifestação de estresse hídrico o que, juntamente com a condição nutricional adequada fornecida pelo biofertilizante bovino, fornece condições para a manutenção do metabolismo fotossintético, conforme tendência evidenciada para a $\mathrm{C}_{\mathrm{i}}$ nesse estádio fenológico.

$\mathrm{Na}$ avaliação ao final do experimento, o uso da água de salinidade elevada na irrigação do maracujazeiro amarelo proporcionou uma elevação de $13,2 \%$ na $C_{i}$, com valores de $229,4 \mu \mathrm{mol} \mathrm{mol}^{-1}$, nas plantas irrigadas com água de $0,5 \mathrm{dS} \mathrm{m}^{-1}$, e $259,7 \mu \mathrm{mol} \mathrm{mol}^{-1}$ nas sob estresse salino (Figura 5B), caracterizando os efeitos negativos da salinidade excessiva no metabolismo do carbono nas plantas.

Valores considerados elevados na $\mathrm{C}_{i}$ no interior das folhas indicam que o $\mathrm{CO}_{2}$ não está sendo utilizado para a síntese de açúcares pelo processo fotossintético, com acúmulo deste gás, indicando que algum fator não estomático está interferindo nesse processo (LARCHER, 2006), o que foi confirmado com a depleção na eficiência fotossintética das plantas irrigadas com água de alta salinidade (Figura 5A).

Os tratamentos avaliados não exerceram efeitos significativos na condutância estomática $\left(\mathrm{g}_{\mathrm{s}}\right)$ no início da floração das plantas. Nas plantas irrigadas com água de baixa salinidade, no solo sem biofertilizante de esterco bovino, $\mathrm{a}_{\mathrm{s}}$ seguiu a tendência de elevação com uso da cobertura morta de 0,18 para $0,34 \mathrm{~mol} \mathrm{~m}^{-2} \mathrm{~s}^{-1}$. Com a aplicação do biofertilizante, a condutância estomática tendeu a aumentar com a cobertura morta de 0,25 para $0,30 \mathrm{~mol} \mathrm{~m} \mathrm{~m}^{-2} \mathrm{~s}^{-1}$. Tendências semelhantes foram observadas nos tratamentos com água salina, com

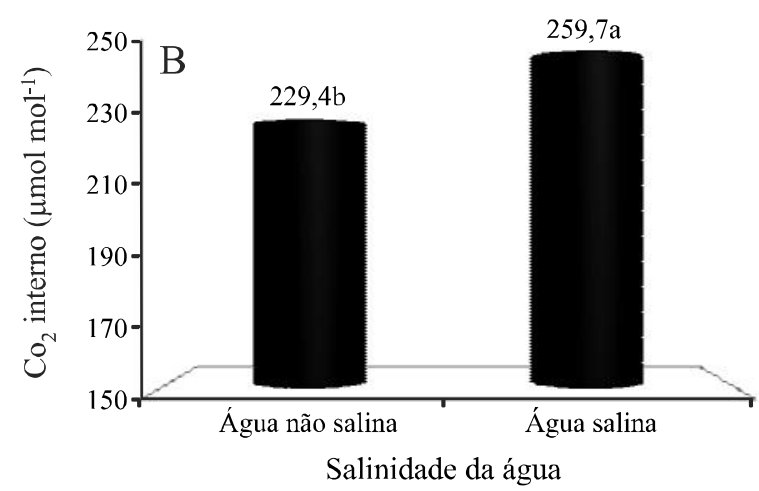

valores de $\mathrm{g}_{s}$ variando de 0,17 a 0,24 , respectivamente, sem biofertilizante e sem e com cobertura morta.

De acordo com a Figura 6, nas plantas irrigadas com água de baixa salinidade e com cobertura morta, a condutância estomática das folhas foi elevada de 0,03 , no solo sem biofertilizante bovino, a $0,08 \mathrm{~mol} \mathrm{~m}^{-2} \mathrm{~s}^{-1}$, no solo com biofertilizante bovino.

No solo com cobertura morta, as plantas irrigadas com água salina apresentaram elevação da $\mathrm{g}_{s}$ de 0,02 a $0,04 \mathrm{~mol} \mathrm{~m}^{-2} \mathrm{~s}^{-1}$, com acréscimos de $100 \%$, com a aplicação do biofertilizante. Esses resultados, provavelmente, sejam em razão dos efeitos do insumo orgânico no estado nutricional das plantas em decorrência da atenuação da ação depressiva dos sais às plantas (BAALOUSHA et al., 2006) e da cobertura morta, com interferência direta nas relações hídricas. A cobertura morta altera a relação solo-água, reduzindo a evapotranspiração e proporcionando menor consumo hídrico das plantas (LYRA et al., 2010).

Flexas et al. (2008), Silveira et al. (2010) e Kusvuran (2012) afirmam que a salinidade elevada da água de irrigação exerce efeito prejudicial no processo de abertura estomática das plantas, por aumentar a resistência à difusão de $\mathrm{CO}_{2}$, o que foi observado nas plantas irrigadas com a água de $4,5 \mathrm{dS} \mathrm{m}^{-1}$, principalmente nas plantas com biofertilizante e cobertura morta, em que $\mathrm{g}_{s}$ foi reduzida de 0,08 , nas plantas irrigadas com água de baixa salinidade, para $0,04 \mathrm{~mol} \mathrm{~m}^{-2} \mathrm{~s}^{-1}$, nas irrigadas com água de alta salinidade. Silva et al. (2011) reportam que ocorre a diminuição da fotossíntese, associada a baixa condutância estomática foliar, em plantas submetidas a condições de salinidade hídrica. 
Figura 6 - Condutância estomática em folhas de maracujazeiro amarelo sob irrigação com águas de baixa e alta salinidade, sem e com biofertilizante bovino e cobertura morta no encerramento da fase produtiva. Médias seguidas de mesmas letras, maiúsculas nas mesmas condições de salinidade da água e de uso de biofertilizante dentro de cobertura morta; minúsculas mesmas condições de salinidade da água e de uso de cobertura morta e mesmas letras gregas entre diferentes condições de salinidade da água e mesmas condições de uso do biofertilizante e cobertura morta, não diferem estatisticamente entre si. DMS $=0,011$

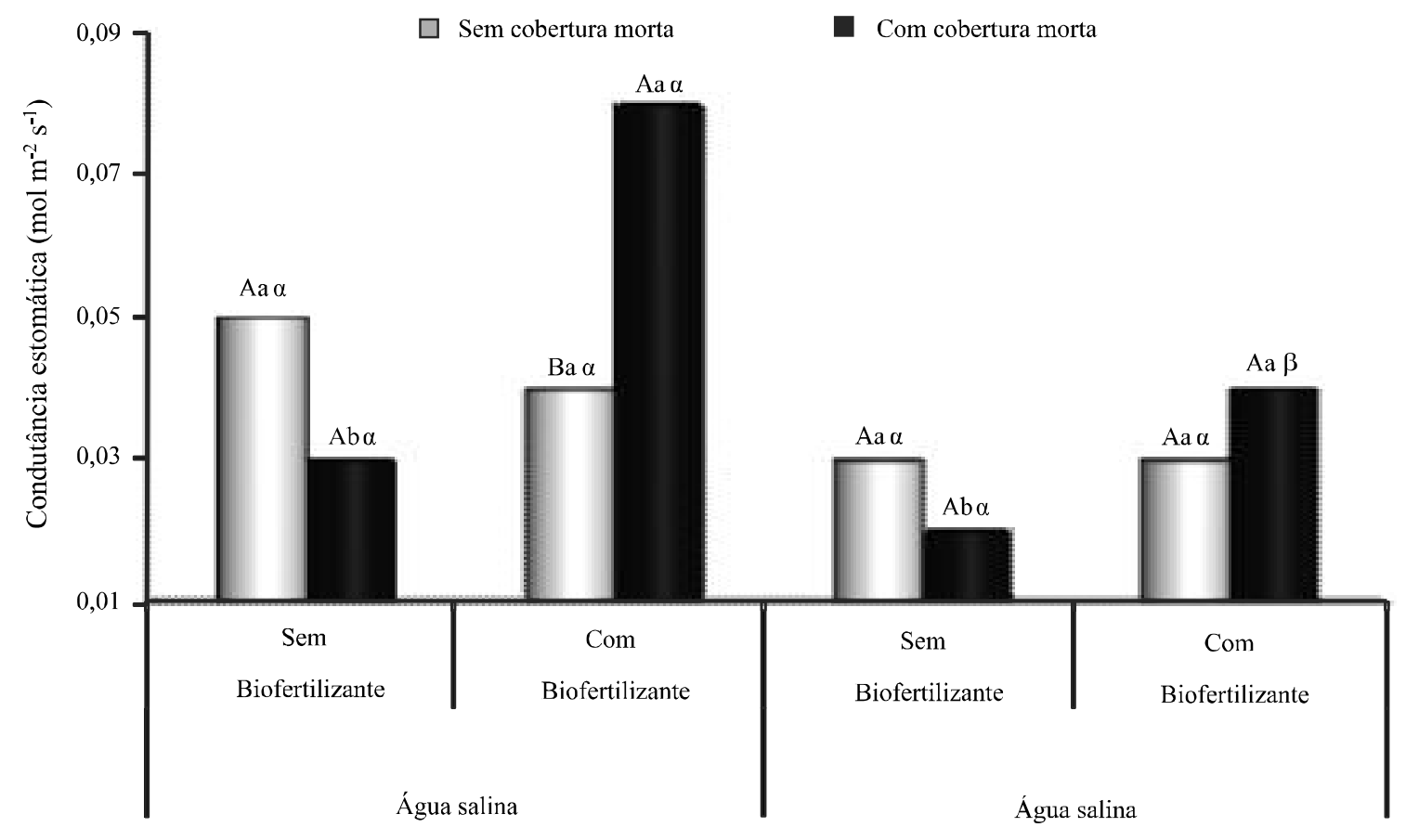

No estádio de floração das plantas não houve efeitos significativos dos tratamentos na taxa transpiratória das plantas, com valores oscilando de 2,00 a $3,33 \mathrm{mmol} \mathrm{m} \mathrm{m}^{-2} \mathrm{~s}^{-1}$, nas plantas irrigadas com água de baixa salinidade, sem biofertilizante bovino e, respectivamente, sem e com cobertura morta, evidenciando as mesmas tendências da condutância estomática.

Na Figura 7, verifica-se que, ao final do experimento, a aplicação do biofertilizante no solo sem a cobertura morta, inibiu em $36,3 \%$ os valores de taxa transpiratória das plantas, sendo diminuída de 1,35 para $0,86 \mathrm{mmol} \mathrm{m}^{-2} \mathrm{~s}^{-1}$. De modo inverso, com utilização da cobertura morta, a taxa transpiratória foi elevada de 1,12 para $1,70 \mathrm{mmol} \mathrm{m}^{-2} \mathrm{~s}^{-1}(51,7 \%)$, o que evidencia os benefícios do uso concomitante do insumo orgânico e cobertura do solo em maracujazeiro amarelo.

Nos tratamentos com biofertilizante bovino, observou-se incremento de $97,7 \%$ nos valores de taxa transpiratória das plantas com a utilização da cobertura morta, onde a elevação foi de 0,86 para $1,70 \mathrm{mmol} \mathrm{m}^{-2} \mathrm{~s}^{-1}$.

Esse comportamento confirma os dados obtidos de gs (Figura 6), ratificando a importância do uso da cobertura morta e disposição do biofertilizante bovino às plantas. Com isso, ocorreu, provavelmente, melhoria nas condições hídricas do solo e, consequentemente, das plantas, possibilitando as trocas gasosas entre as plantas e o meio, evitando estresse hídrico. Redução na taxa de transpiração, com consequente queda na condutância estomática e taxa de fotossíntese, induzida por estresse hídrico e salino, foi observada em pinhão manso por Silva et al. (2010).

A taxa fotossintética das plantas não foi influenciada pelos tratamentos na fase de floração, com tendências de elevação semelhantes às observadas para $\mathrm{g}_{\mathrm{s}}$ e taxa transpiratória, com valores de 10,12 (plantas irrigadas com água de alta salinidade, com biofertilizante e sem cobertura morta) a $18,37 \mu$ mol $\mathrm{CO}_{2} \mathrm{~m}^{2} \mathrm{~s}^{-1}$ (plantas irrigadas comágua de baixa salinidade, sem biofertilizante e com cobertura morta).

Em função da redução da condutância estomática (Figura 6), da taxa transpiratória (Figura 7) e do aumento da concentração interna de $\mathrm{CO}_{2}$ (Figura 5-B) nas folhas, a taxa de assimilação líquida foi comprometida quando as plantas foram irrigadas com água de alta salinidade (Figura 8). As plantas irrigadas com água de alta salinidade apresentaram valores inferiores de 
Figura 7 - Taxa transpiratória no encerramento da fase produtiva do maracujazeiro amarelo em solo sem e com biofertilizante e cobertura morta. Médias seguidas de mesmas letras, minúsculas entre diferentes condições do uso da cobertura morta dentro das mesmas condições do uso do biofertilizante bovino e maiúsculas entre a mesma condição do uso da cobertura morta dentro de diferentes condições do uso de biofertilizante bovino não diferem estatisticamente entre si. DMS $=0,31$

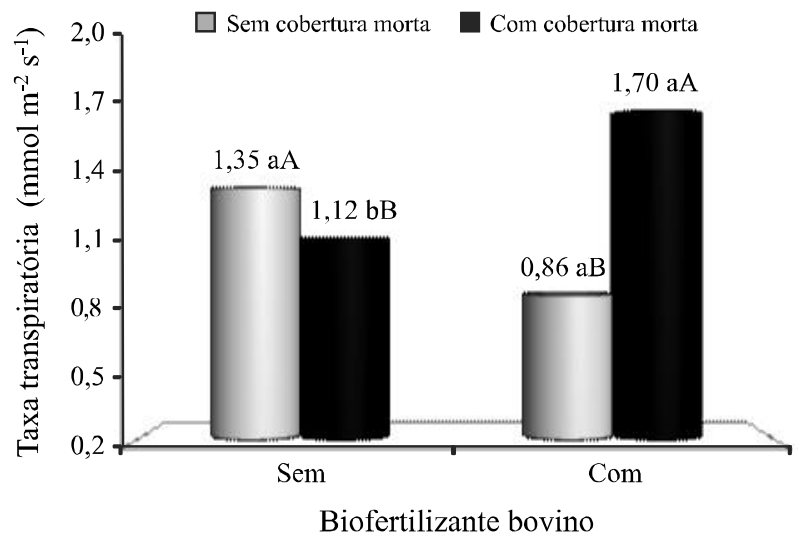

Figura 8 - Fotossíntese líquida no encerramento da fase produtiva do maracujazeiro amarelo irrigado com águas de baixa e alta salinidade. Médias seguidas de mesmas letras não diferem estatisticamente entre si. DMS $=0,73$

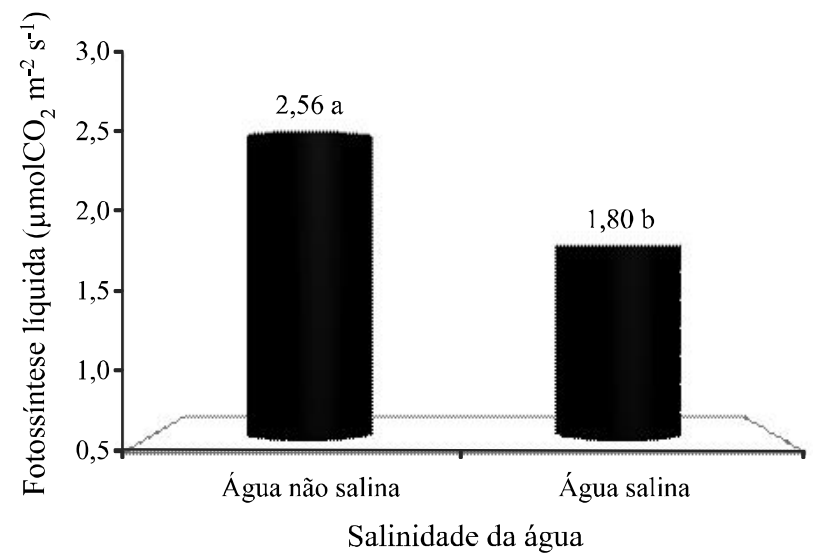

taxa fotossintética líquida $\left(1,80 \mu \mathrm{mol} \mathrm{CO}_{2} \mathrm{~m}^{2} \mathrm{~s}^{-1}\right)$ aos verificados em plantas irrigadas com água de baixa salinidade $\left(2,56 \mu \mathrm{mol} \mathrm{CO} \mathrm{m}^{2} \mathrm{~s}^{-1}\right)$, com redução de $30 \%$, ao final do experimento.

O estresse salino reduz a taxa de assimilação líquida de $\mathrm{CO}_{2}$, taxa de transpiração e condutância estomática em glicófitas. Uma consequência indireta do fechamento estomático é a restrição à entrada de $\mathrm{CO}_{2}$ nas células, o que poderia aumentar a susceptibilidade a danos fotoquímicos, pois baixas taxas de assimilação do $\mathrm{CO}_{2}$ causam energia luminosa excessiva no $\mathrm{FS}_{\mathrm{II}}$ (SILVA et al., 2010). Distúrbios nas reações fotoquímicas causadas em glicófitas pelo estresse salino foram verificados por Tezara et al. (2005), Lucena (2009) e Chaum e Kirdmanee (2011), o que foi comprovado com os resultados do rendimento quântico potencial $\left(\mathrm{F}_{\mathrm{v}} / \mathrm{F}_{\mathrm{m}}\right)$ nas plantas de maracujazeiro amarelo irrigadas com água de salinidade elevada (Figura 4A).

\section{CONCLUSÕES}

1. A irrigação com água de baixa salinidade e aplicação de biofertilizante bovino comum, em geral, estimularam a eficiência fotossintética das plantas;

2. O uso simultâneo de água de alta salinidade, biofertilizante e cobertura morta proporcionou a redução da condutância estomática do maracujazeiro amarelo;

3. O estresse salino inibiu a atividade fotoquímica do fotossistema II e fotossíntese líquida das plantas;

4. O maracujazeiro amarelo apresentou maior eficiência do aparelho fotossintético quando submetido à associação da cobertura morta, biofertilizante bovino e irrigação com água de baixa salinidade.

\section{AGRADECIMENTOS}

Os autores expressam seus agradecimentos ao $\mathrm{CNPq}$ (Conselho Nacional de Desenvolvimento Científico e Tecnológico) e o INCTSal (Instituto Nacional de Ciência e Tecnologia em Salinidade) pelo financiamento concedido para realização do trabalho.

\section{REFERÊNCIAS}

BAALOUSHA, M.; MOTELICA-HEINO, M.; COUSTUMER, P. Conformation and size of humic substances: effects of major cátion concentration and type, $\mathrm{pH}$, salinity, and resistence time. Coloids and Surface A: Physicochemical Engineering Aspects, v. 272, n. 1, p. 48-55, 2006.

BANZATTO, D. A.; KRONKA, S. N. Experimentação Agrícola. 4. Jaboticabal: FUNEP, 2006, 247 p.

BOLHÀR-NORDENKAMPF, H. R. et al.; Chlorophyll fluorescence as probe of the photosynthetic competence of leaves in the field: a review of current instrumentation. Functional Ecology, v. 3, n. 1, p. 497-514, 1989.

CAVAlCANTE, L. F. et al. Clorofila e carotenoides em maracujazeiro-amarelo irrigado com águas salinas no solo com biofertilizante bovino. Revista Brasileira de Fruticultura, v. 33, supl. 1, p. 699-705, 2011. 
CAVAlCANTE, L. F. et al. Crescimento e produção do maracujazeiro amarelo em solo de baixa fertilidade tratado com biofertilizantes líquidos. Revista Brasileira de Ciências Agrárias, v. 2, n. 1, p. 15-19, 2007.

CHA-UM, S.; KIRDMANEE, C. Remediation of salt-affected soil by the addition of organic matter: an investigation into improving glutinous rice productivity. Scientia Agricola. v. 68, n. 4 , p. $406-410,2011$.

COELHO, M.A.; SONCIN, N. B. Geografia do Brasil. 1. ed. São Paulo: Ed. Moderna, 1982. 368 p.

CORREIA, K. G. et al. Crescimento, produção e características de fluorescência da clorofila a em amendoim sob condições de salinidade. Revista Ciência Agronômica, v. 40, n. 4, p. 514-521, 2009.

DIAS, T. J. et al. Produção do maracujazeiro e resistência mecânica do solo com biofertilizante sob irrigação com águas salinas. Revista Ciência Agronômica, v. 42, n. 3, p. 644-651, 2011

EMBRAPA. Manual de métodos de análise do solo. 2. ed. Rio de Janeiro, 1997. 212 p. (CNPS, Documentos 1).

FALQUETO, A. R. et al. Características da fluorescência da clorofila em cultivares de arroz com ciclo precoce, médio e tardio. Revista Brasileira de Biociências, v. 5, supl. 2, p. 579$581,2007$.

FLEXAS, J. et al. Mesophyll conductance to $\mathrm{CO}_{2}$ : current knowledge and future prospects. Plant, Cell e Environment, v. 31, n. 5 , p. 602-628, 2008.

FREIRE, J. L. O. et al. Necessidade hídrica do maracujazeiro amarelo cultivado sob estresse salino, biofertilização e cobertura do solo. Revista Caatinga, v. 24, n. 1, p. 82-91, 2011.

FREIRE, J. L. O. et al. Atributos qualitativos do maracujá amarelo produzido com água salina, biofertilizante e cobertura morta no solo. Revista Brasileira de Ciências Agrárias, v. 5, n. 1, p. 102-110, 2010.

KONRAD, M. L. F. et al. Trocas gasosas e fluorescência da clorofila em seis cultivares de cafeeiro sob estresse de alumínio. Bragantia, v. 64, n. 3, p. 339-347, 2005.

KUSVURAN, S. Effects of drought and salt stresses on growth, stomatal conductance, leaf water and osmotic potentials of melon genotypes (Cucumis melo L.). African Journal Agricultural Research, v. 7, n. 5, p. 775-781, 2012.

LARCHER, W. Ecofisiologia vegetal. 1. ed. São Carlos: Rima, 2006. 531 p.

LUCENA, C. C. Crescimento vegetativo, absorção de nutrientes e trocas gasosas em mangueiras submetidas a estresse salino. 2009. 178f. Dissertação (Mestrado em Fitotecnia) - Centro de Ciências Agrárias, Universidade Federal de Viçosa, Viçosa, 2009.
LYRA, G. B. et al. Conteúdo de água no solo em cultivo de milho sem e com cobertura morta na entrelinha na região de Arapiraca-AL. Irriga, v. 15, n. 2, p. 173-183, 2010.

MAXWELL, K.; JOHNSON, G. N. Chlorophyll fluorescence - a practical guide. Journal of Experimental Botany, v. 51, n. 345, p. 659-668, 2000.

MELO, A. S. et al. Crescimento vegetativo, resistência estomática, eficiência fotossintética e rendimento do fruto da melancieira em diferentes níveis de água. Acta Scientiarum Agronomy, v. 32, n. 1, p. 73-79, 2010.

PERES, J. G.; SOUZA, C. F.; LAVORENTI, N. A. Avaliação dos efeitos da cobertura de palha de cana-de-açúcar na umidade e na perda de água do solo. Engenharia Agrícola. v. 30, n. 5, p. 875-886, 2010.

RICHARDS, L. A. Diagnostico y rehabilitacion de suelos salinos y sodicos. Departamento de Agricultura de los Estados Unidos de la America, 1954, 172 p.

SANTOS, A. C. V.; AKIBA, F. Biofertilizante líquido: uso correto na agricultura alternativa. 1. ed. Seropédica: UFRRJ. $1996.35 \mathrm{p}$.

SANTOS,H.G.;JACOMINE,P.K.T.;ANJOS,L.H.C.; OLIVEIRA, V. A.; OLIVEIRA, J. B.; COELHO, M. R.; LUMBREBAS, J. F.; CUNHA, J. T. F. (Eds). Sistema brasileiro de classificação de solos. 2. ed. Rio de Janeiro: Embrapa Solos. 2006. 306 p.

SILVA, E. N. et al. Comparative effects of salinity and water stress on photosynthesis, water relations and growth of Jatropha plants. Journal of Arid Environments, v. 74, n. 10, p. 1130-1137, 2010.

SILVA, E. N. et al. Salt stress induced damages on the photosynthesis of physic nut young plants. Scientia Agricola. v. 68, n. 1, p. 62-68, 2011.

SILVEIRA, J. A. G.; SILVA, S. L. F.; SILVA, E. N.; VIÉGAS, R. A. Mecanismos biomoleculares envolvidos com a resistência ao estresse salino em plantas. In: GHEYI, H. R.; DIAS, N. S.; LACERDA, C. F. (editores). Manejo da salinidade na agricultura: estudos básicos e aplicados. 1. ed. Fortaleza: INCTSal. 2010. cap. 11, p. 161-18.

SOUSA, G. G. et al. Crescimento inicial do milho sob diferentes concentrações de biofertilizante bovino irrigado com águas salinas. Revista Ciência Agronômica, v. 43, n. 2, p. 237-245, 2012.

TESTER, M.; BACIC, A. Abiotic stress tolerance in grasses. From model plants to crop plants. Plant Physiology, v. 137, p. 791-793, 2005.

TEZARA, W. et al. Photosynthesis and photoinhibition in two xerophytic shrubs during drought. Photosynthetica, v. 43, n. 1, p. 37-45, 2005.

ZANANDREA, I. et al. Efeito da salinidade sob parâmetros de fluorescência em Phaseolus vulgaris. Revista Brasileira Agrociência, v. 12, n. 2, p. 157-161, 2006. 